\title{
Essential role of BETA2/NeuroD1 in development of the vestibular and auditory systems
}

\author{
Min Liu, ${ }^{1}$ Fred A. Pereira, ${ }^{1}$ Steven D. Price, ${ }^{2}$ Mei-jin Chu, ${ }^{1}$ Cindy Shope, ${ }^{3}$ Donna Himes, ${ }^{3}$ \\ Ruth Anne Eatock, ${ }^{3}$ William E. Brownell, ${ }^{3}$ Anna Lysakowski, ${ }^{2}$ and Ming-Jer Tsai ${ }^{1,4,5}$ \\ ${ }^{1}$ Department of Molecular and Cellular Biology, Baylor College of Medicine, Houston, Texas 77030, USA; ${ }^{2}$ Department \\ of Anatomy and Cell Biology, University of Illinois at Chicago, Chicago, Illinois 60612, USA; ${ }^{3}$ The Bobby R. Alford \\ Department of Otorhinolaryngology and Communicative Sciences, and the Division of Neuroscience, Baylor College \\ of Medicine, Houston, Texas 77030, USA; ${ }^{4}$ Department of Medicine and Program in Developmental Biology, Baylor College \\ of Medicine, Houston, Texas 77030, USA
}

BETA2/NeuroD1 is a bHLH transcription factor that is expressed during development in the mammalian pancreas and in many locations in the central and peripheral nervous systems. During inner ear ontogenesis, it is present in both sensory ganglion neurons and sensory epithelia. Although studies have shown that BETA2/NeuroD1 is important in the development of the hippocampal dentate gyrus and the cerebellum, its functions in the peripheral nervous system and in particular in the inner ear are unclear. Mice carrying a BETA2/NeuroD1 null mutation exhibit behavioral abnormalities suggestive of an inner ear defect, including lack of responsiveness to sound, hyperactivity, head tilting, and circling. Here we show that these defects can be explained by a severe reduction of sensory neurons in the cochlear-vestibular ganglion (CVG). A developmental study of CVG formation in the null demonstrates that BETA2/NeuroD1 does not play a primary role in the proliferation of neuroblast precursors or in their decision to become neuroblasts. Instead, the reduction in CVG neuron number is caused by a combination both of delayed or defective delamination of CVG neuroblast precursors from the otic vesicle epithelium and of enhanced apoptosis both in the otic epithelium and among those neurons that do delaminate to form the CVG. There are also defects in differentiation and patterning of the cochlear duct and sensory epithelium and loss of the dorsal cochlear nucleus. BETA2/NeuroD1 is, thus, the first gene to be shown to regulate neuronal and sensory cell development in both the cochlear and vestibular systems.

[Key Words: BETA2/NeuroD1; CVG; hair cells; inner ear; delamination]

Received August 4, 2000; revised version accepted October 6, 2000.

The mammalian inner ear is a complex and delicate sensory organ for hearing and balance. The cochlea is responsible for auditory sensation, the otolith organs (utricle and saccule) detect linear acceleration and head position with respect to gravity, and the semicircular canals detect angular head movements. Development of the inner ear begins as an ectodermal thickening, leading to a placode lateral to the rhombencephalon, which subsequently invaginates to form a rudimentary structure, the otocyst (otic vesicle; Sher 1971; Rubel 1978). The cochlear and vestibular sensory epithelia and the respective ganglia are all derived from the otocyst (Noden and Van de Water 1992; Bissonnette and Fekete 1996). Development of the otocyst requires intrinsic and extrinsic factors that regulate proliferation, differentiation, and

${ }^{5}$ Corresponding author.

E-MAIL mtsai@bcm.tmc.edu; FAX (713) 790-1275.

Article and publication are at www.genesdev.org/cgi/doi/10.1101/ gad.840500. apoptosis to form the mature three-dimensional inner ear structures (Van de Water and Represa 1991; Fekete 1996). The otic epithelium becomes polarized and cell fate is determined at an early stage of development (Li et al. 1978; Anniko and Wikstrom 1984; Morsli et al. 1998). The first lineage to differentiate is the sensory neuronal precursors that form the cochlear-vestibular ganglion (CVG, ganglion of cranial nerve VIII; Hemond and Morest 1991). Specification of the neuroblast lineage occurs immediately after, if not simultaneously with, the irreversible determination of the otic placodal field (E8 in mice; Jacobson 1963; Swanson et al. 1990). Formation of the CVG starts between embryonic day (E) 9 and E9.5, when neuronal progenitors delaminate from the otic placode, migrate toward the ventral side of the otocyst, and aggregate to form the ganglion primordium.

More and more genes are being found to be involved in inner ear development, and mutations in some of these genes result in sensory receptor cell and/or neuronal ab- 
normalities in the cochlear and/or vestibular systems (for reviews, see Torres and Giraldez 1998; Holme and Steel 1999). These defects result from failure in various steps of inner ear development, such as (1) inductive signal(s) from the neural tube (e.g., Hoxa-1, fgf-3; Chisaka et al. 1992; Vendrell et al. 2000); (2) field specification (e.g., ear vs. eye, $d l \times 3$ and six1); (3) regional and cell-fate determination (e.g., $R A R \alpha / \gamma, P a x 2, B r n 3.1, N k x 5.1, N g n 1$, Otx-1, and Otx-2 and Math1; Lohnes et al. 1994; Erkman et al. 1996; Torres et al. 1996; Hadrys et al. 1998; Ma et al. 1998; Wang et al. 1998; Morsli et al. 1999; Bermingham et al. 1999); (4) target-derived neurotrophic support for vestibular and cochlear sensory neurons (neurotrophins and their receptors; Minichiello et al. 1995; Bianchi et al. 1996; Farinas and Rechardt 1996); and (5) functionality (e.g., TRß, KCNQ4; (Rüsch et al. 1998a; Kubisch et al. 1999). However, to date, no genes have been identified to regulate both sensory hair cell and neuronal development simultaneously in the vestibular and auditory systems.

BETA2/NeuroD1 is a tissue-specific basic helix-loophelix transcription factor originally cloned in our laboratory by its ability to up-regulate insulin gene expression (Naya et al. 1995). It was also cloned (Lee et al. 1995) as a gene required for neuronal differentiation, named NeuroD; we now refer to the gene as BETA2/NeuroD1. Like many bHLH family members that play important roles in regulating various developmental systems (Jan and Jan 1993), BETA2/NeuroD1 is essential for development of the pancreas and brain. Our laboratory has shown that the pancreatic islet cells in the BETA2/NeuroD1 null are not properly maintained and undergo apoptosis. Morphogenesis of the islet itself is also defective in the null (Naya et al. 1997). In addition, both the secretinand cholecystokinin-expressing enteroendocrine cells are missing in the null gut (Mutoh et al. 1998). Ectopic overexpression of BETA2/NeuroD1 in Xenopus embryos promotes neurogenesis and induces premature differentiation of neuronal precursors (Lee et al. 1995). Finally, the granule cells of the cerebellum and hippocampal dentate gyrus in the null fail to differentiate properly and are present in greatly reduced numbers (Miyata et al. 1999; Liu et al. 2000; Schwab et al. 2000). Thus, both gain-offunction and loss-of-function experiments have implicated BETA2/NeuroD1 in promoting cell cycle withdrawal and cellular differentiation. However, recent results both from our laboratory (see below) and others (Miyata et al. 1999; Lee et al. 2000; Liu et al. 2000) have revealed that $B E T A 2 / N e u r o D 1$ expression is not restricted to postmitotic neurons but is also detected in proliferating neural precursor cells in some tissues.

In this study, we have analyzed the auditory and vestibular defects in the BETA2/NeuroD1 null. Our results indicate that BETA2/NeuroD1 is required for neurogenesis of the cochlear-vestibular ganglion. During inner ear development, BETA2/NeuroD1 expression is first detected prominently within the otic vesicle wall. This expression is first seen in the sensory neuroblast precursors (E8.75) and later (E13.5 and E15.5) in sensory epithelia of both vestibular organs and the cochlea. Adult
BETA2/NeuroD1 null animals displayed an $80 \%$ decrease in vestibular ganglion neurons as compared to the controls, while there was an almost total loss $(>95 \%)$ of cochlear ganglion neurons. A detailed developmental study in the null demonstrates that BETA2/NeuroD1 does not act either by reducing the proliferation of neuroblast precursors or by changing their decision to become neuroblasts. Instead, the early CVG deficit is attributed to the failed delamination of CVG neuroblasts from the otic vesicle wall. At later stages, inadequate trophic support by the peripheral targets and excess apoptosis also contribute to the great reduction in CVG neurons. Examination of the sensory epithelia showed that there was misalignment, misplacement, and duplication of hair cells in the organ of Corti in the null. Phenotypically, the BETA2/NeuroD1 null is completely deaf and suffers from severe deficiencies in balance and coordination. Taken together, these data establish BETA2/NeuroD1 as a critical gene for development of the auditory and vestibular systems.

\section{Results}

Defects in balance and hearing

As reported previously (Liu et al. 2000), we have established a BETA2/NeuroD1 null mouse line that survives to adulthood and is fertile. However, the null mothers do not nurse their pups, possibly because of CNS and/or sensory defects. The null animals were generally underweight and more susceptible to parasitic infection. By 7-10 d of age, all surviving null animals show deficits in balance, manifested by head tilting, lack of coordination, and an inability to right themselves when laid on their sides or backs (but they all learned this skill by 1 mo of age). Between weeks two and three, they displayed abnormal hyperactivity and circling behavior. BETA2/NeuroD1 is expressed in sensory organs such as the eye (Morrow et al. 1999), olfactory bulb (Lee et al. 2000) and the inner ear (this study). As circling behavior is a characteristic of mouse mutants with inner ear defects (Gibson et al. 1995; Bussoli et al. 1997; Rogers et al. 1999), we first examined the hearing abilities of the BETA2/NeuroD1 null by measuring the auditory brainstem responses (ABR) evoked by acoustic transients (clicks). The ABR consists of multiple waves: Wave 1 is believed to reflect activation of the primary afferent nerve terminals in brainstem nuclei, and wave 2 reflects activation of the cochlear nuclear complex (Mitchell and Clemis 1977). The null showed no click-evoked ABR at any stimulus level, even up to a value that is $25 \mathrm{~dB}$ more intense than the mean threshold for wild-type littermates (Fig. 1). This indicates complete deafness in the null. Interestingly, heterozygotes had a significantly higher threshold (15 dB higher) than the wild type. The fact that the null lacked any $\mathrm{ABR}$ indicates that the hearing deficit may occur in the auditory pathway as early as in the cochlear afferent nerve fibers and, possibly, in the cochlea.

In addition to the spontaneous seizures (Liu et al. 


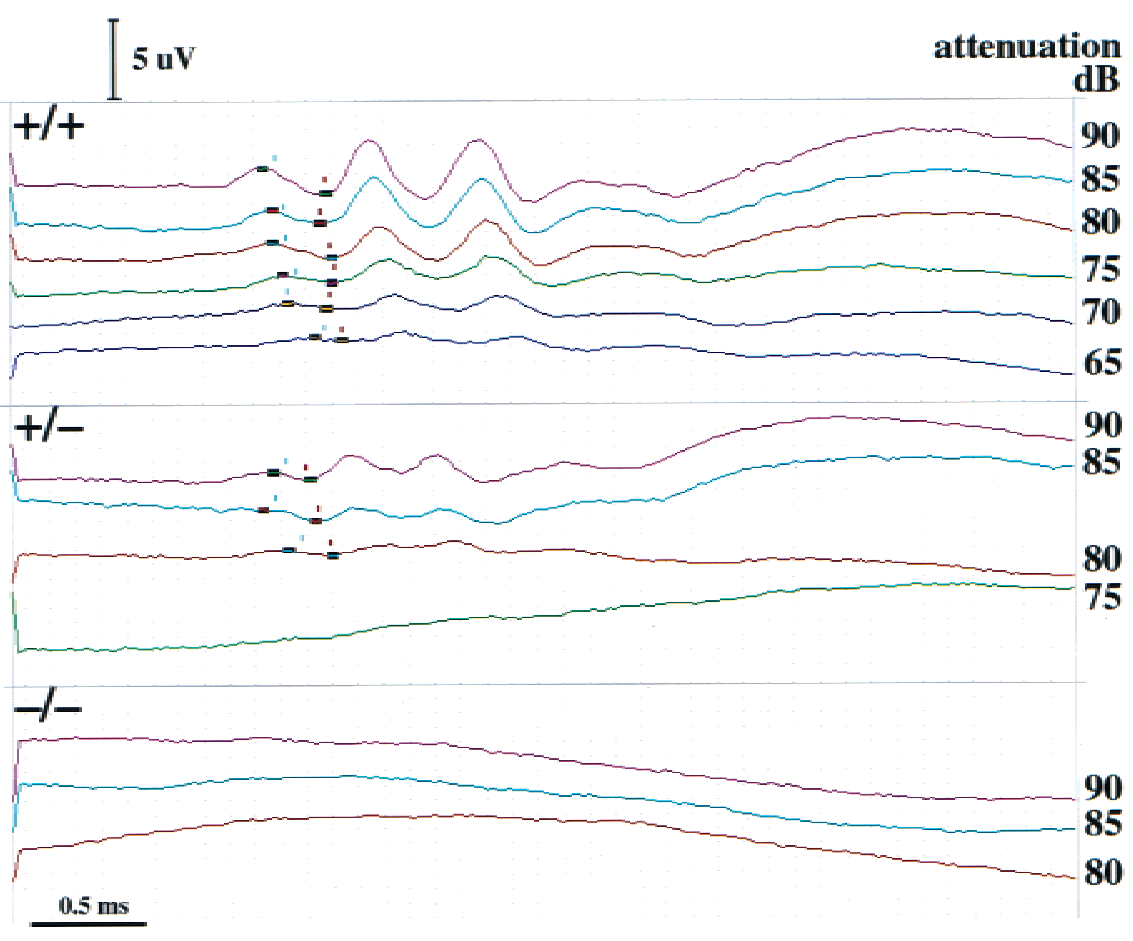

Figure 1. Complete deafness in the BETA2/NeuroD1 null. Representative waveforms of auditory brainstem responses (ABR) to click stimuli from wild-type, heterozygous, and homozygous BETA2/ NeuroD1 mice at $10 \mathrm{wk}$ of age are shown at different stimulus intensities. The null showed a complete failure to produce any $\mathrm{ABR}$, while heterozygotes revealed a significantly higher mean ABR threshold ( $80 \mathrm{~dB}$ re: $1 \mathrm{mV}$ input to the speaker) than for wild-type mice $(65 \mathrm{~dB}, P<0.05$, twotail Student's $t$-test with six or more animals in each group). I, wave 1 ; II, wave 2 .
2000) and circling behavior, the null showed severe ataxia reflecting a cerebellar defect (Miyata et al. 1999; M. Liu and M.-J. Tsai, unpubl.). Therefore, some of the classical balance tests such as the rotarod test could not be performed. However, abnormal vestibular function in the null was clearly indicated by the circling behavior and lack of a righting reflex. Also, when suspended by their tails, the null animals displayed a hindlimb clutching response indicative of impaired motor coordination (Crawley and Paylor 1997). Therefore, the BETA2/NeuroD1 null has severe defects both in the cochlea and the vestibule.

\section{Reduction of vestibular and spiral ganglion neurons}

The behavioral and electrophysiological defects in the BETA2/NeuroD1 null are consistent with inner ear abnormalities. Histological examination revealed that the most dramatic sensory deficit was the severe loss of neurons in the cochlear and vestibular ganglia. The cell bodies of the primary auditory neurons (spiral ganglion) are located within the cochlear modiolus, while primary vestibular neurons (Scarpa's ganglion) are located in the internal auditory meatus. During embryonic and early postnatal stages, these neurons undergo proliferation, axonal growth, and apoptosis, reaching maturity by 2 wk of age (Altman and Bayer 1982; Anniko 1983). At P8, the BETA2/NeuroD1 null already showed significant reductions in the number of vestibular ganglion neurons (VG; $85 \%$ reduction in Fig. $2 \mathrm{a}, \mathrm{b})$ and cochlear ganglion neurons (CG; 95\% in Fig. 2c-f). Also, axon fibers from these neurons were obviously reduced in number in the null (Fig. 2b,f). Table 1 summarizes the reduction in neurons at different embryonic and neonatal stages. By E13, there was already a $\sim 30 \%$ and $\sim 40 \%$ loss of CG and VG neurons, respectively. We suspect that the decrease in ganglion neurons was not caused solely by degeneration, as the decrease was observed as early as E9.5, when development of the cochlear-vestibular ganglion complex (CVG) begins (see below). At the cellular level, the residual ganglion neurons appeared unhealthy and lacked nucleolar staining but did have inclusion bodies (see insert in Fig. 2b). Aside from the loss of afferent innervation (cf. Fig. 2e and f), the organ of Corti was grossly intact in the null (Fig. 2d,f; although scanning electron microscopy revealed some defects that will be discussed in a later section).

\section{BETA2/NeuroD1 expression in the developing inner ear}

Once the otic anlage is set up (E8.5 in mice), cells of the otic vesicle proliferate and undergo complex morphogenetic changes and programmed cell death. The outgrowth of the future cochlea is from the ventromedial part of the otocyst, while the dorsolateral wall of the otocyst later gives rise to the vestibular apparatus (Fekete 1996). To understand the defects in the null, we examined the expression pattern of BETA2/NeuroD1 in the developing inner ear. $\beta$-galactosidase ( $\beta$-gal) expressed from the BETA2/NeuroD1 locus was used to monitor BETA2/NeuroD1 expression in heterozygotes (Naya et al. 1997). The expression in the ear anlage was detected as early as E8.75, the otic cup stage (data not shown). At E9, when cranial nerve VIII neurons begin to differentiate, prominent BETA2/NeuroD1 expression was observed in the ventral part of the otic vesicle (Fig. 


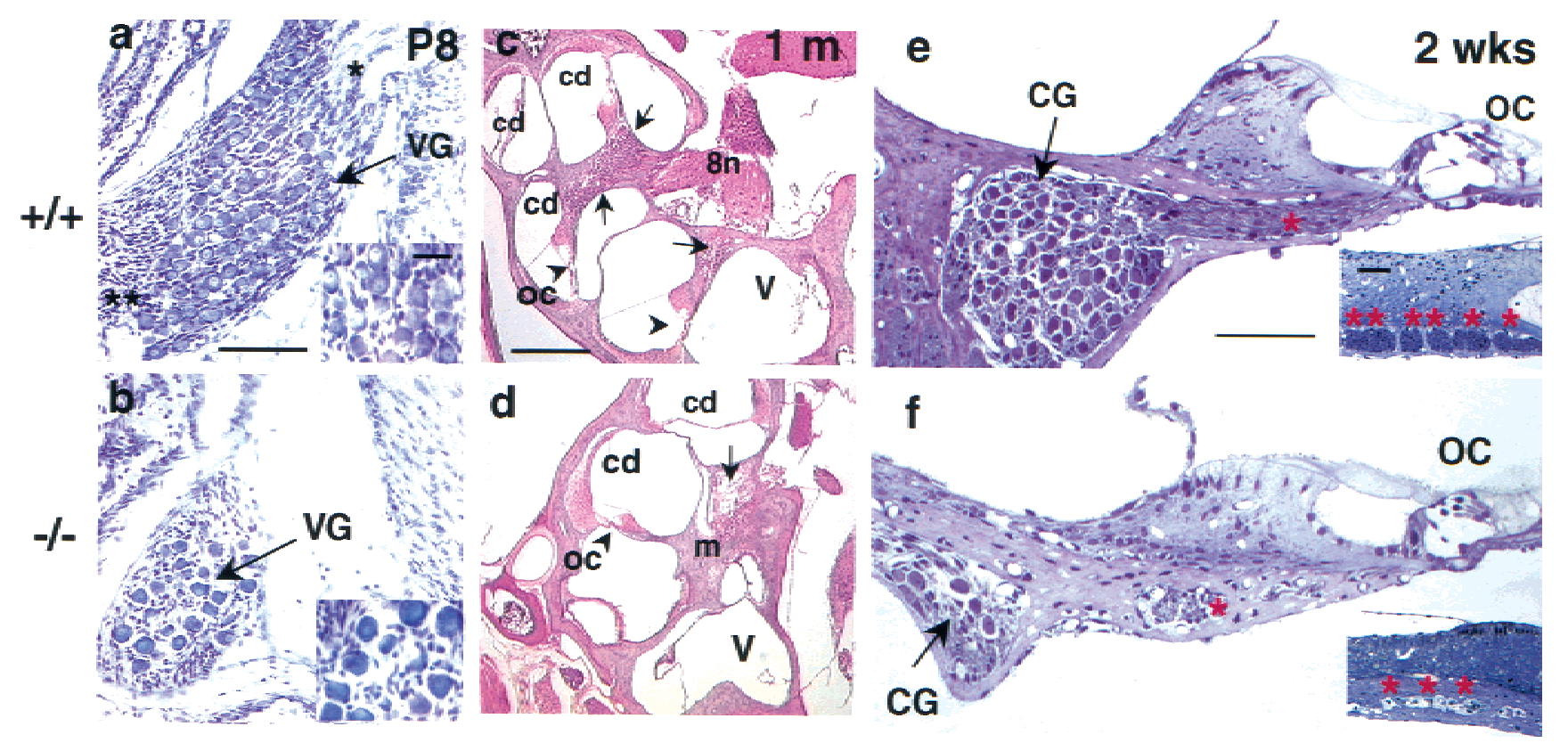

Figure 2. Severe loss of cochlear and vestibular ganglia in mutants. Histological analysis of vestibular ganglion neurons: $(a, b)$ Cresyl violet staining, horizontal section, scale bar $=100 \mu \mathrm{m})$; cochlea at midmodiolar level: $(c, d)$ H\&E staining, sagittal section, scale bar $=0.30 \mathrm{~mm})$; and the organ of Corti: $(e, f)$ toluidine blue semithin section, scale bar $=100 \mu \mathrm{m})$. At P8, the vestibular ganglion (VG) from the control shows dense packing of neuronal cell bodies (arrow in $a$ ) and their axons (asterisk in $a$ ). In the null ganglion $(b)$, there are less than one-fifth the number of cell bodies and corresponding fibers as in the control. The residual mutant vestibular neurons lack clear nucleolar staining (see inserts in $a, b$, scale bar $=30 \mu \mathrm{m})$. At the midmodiolus level of the cochlea in 1-mo-old mice $(c, d)$, the spiral neurons (CG) are abundant in the modiolus (m) of controls but largely missing from the nulls (arrows). This loss of spiral ganglion is more clearly seen in the semithin sections in $e$ and $f$, where the atrophy of axons is also evident (in $e, f$, and their inserts, which are cross sections from $e, f$, scale bar $=200 \mu \mathrm{m})$. The organ of Corti, however, is present in the nulls $(\mathrm{OC}, e, f)$. 8n, VIII nerve; cd, cochlear duct; V, vestibule.

$3 a, c)$, the location of the future CVG and cochlea. The CVG expression persisted throughout its development (Fig. 3b; see Fig. 4). In the vestibular sensory epithelia, BETA2/NeuroD1 expression began at E13-E14 during the onset of hair cell differentiation, and it persisted at least until the sensory structures were well defined. Expression was clearly evident throughout the sensory epithelia of the utricle, saccule (Fig. 3d), and crista ampullaris (Fig. 3e). The expression in the cochlear sensory epithelium (organ of Corti) began at E15.5 and was weak compared to other BETA2/NeuroD1-expressing regions in the inner ear (Fig. 3f,g).

\section{Mechanism of cochlear-vestibular ganglia defects}

The CVG neurons are believed to be primarily of placodal otic origin with a minimal neural crest cell contribution (D'Amico-Martel and Noden 1983; Van De Water 1986). CVG neuroblasts are born in the ventral otocyst wall around E9 and go through a period of intense cell proliferation between E9.5 and E13.5. Then they delaminate from the otic epithelium and differentiate into ganglion neurons (Ruben 1967). The pattern of BETA2/NeuroD1 expression correlates well with CVG ontogenesis. Interspersed patches of BETA2/NeuroD1-expressing cells were initially observed in the ventral side of the otocyst wall (Fig. 3c), where CVG neurons are born and from which cochlear components are derived. The CVG initially forms as one complex that subsequently separates into distinct vestibular and cochlear components. At the beginning of its formation, the CVG complex, as marked by BETA2/NeuroD1 expression, is contiguous at its dorsal edge with the geniculate ganglion (Fig. 4a). Starting from E10.5, the single cell mass of the VII-VIII ganglion complex splits ventrally into a medial part, the acoustic ganglion, and a lateral part, the geniculate ganglion (Fig. 4c). At E11.5, the VIIIth nerve ganglion begins to separate into cochlear and vestibular components (shown at E12.5 in Fig. 4g). The cells of the medial, cochlear portion has more densely packed nuclei than does the lateral, vestibular portion, which has cells with more densely stained cytoplasm. At E13.5, the medial half, the primordium of the cochlear ganglion, terminates in a loop between the ventral end of the saccule and the newly formed half-coil of the cochlear duct (Altman and Bayer 1982). Thus, the spatial and temporal expression of BETA2/NeuroD1 clearly correlated with the generation, delamination, and differentiation of the CVG. Doublestaining for $\beta$-gal and an antibody against a neuron-specific isoform of $\beta$-tubulin, an early pan-neuronal marker, showed that the BETA2/NeuroD1-positive cells within the ventral otocyst wall were also positive for $\beta$-tubulin, confirming their neuronal identity (data not shown). 
Table 1. Neuron counts from the vestibular and cochlear ganglia of BETA2/NeuroD1 mice

\begin{tabular}{lccc}
\hline $\begin{array}{l}\text { Age and } \\
\text { ganglion }\end{array}$ & Wild type ${ }^{\mathrm{a}, \mathrm{b}}$ & Null $^{\mathrm{a}, \mathrm{b}}$ & $\begin{array}{c}\% \\
\text { reduction }\end{array}$ \\
\hline E13: & & & \\
$\quad$ Cochlear & $3212 \pm 262(4)$ & $2248 \pm 118(6)$ & $30^{\star}$ \\
$\quad$ Vestibular & $2860 \pm 161(4)$ & $1716 \pm 212(6)$ & $40^{\star}$ \\
E14.5: & & & \\
$\quad$ Cochlear & $4211 \pm 176(6)$ & $1275 \pm 156(6)$ & $70^{\star \star}$ \\
$\quad$ Vestibular & $3104 \pm 224(6)$ & $1092 \pm 76(6)$ & $65^{\star}$ \\
E16.5: & & & \\
Cochlear & $5562 \pm 156(6)$ & $1206 \pm 205(6)$ & $90^{\star \star}$ \\
Vestibular & $4762 \pm 168(6)$ & $570 \pm 107(6)$ & $75^{\star \star}$ \\
E18.5: & & & \\
Cochlear & $7021 \pm 212(4)$ & $812 \pm 78(4)$ & $95^{\star}$ \\
Vestibular & $5072 \pm 134(4)$ & $355 \pm 112(4)$ & $84^{\star}$ \\
P2: & & & \\
Cochlear & $6850 \pm 121(4)$ & $778 \pm 88(4)$ & $95^{\star \star}$ \\
$\quad$ Vestibular & $4568 \pm 90(4)$ & $345 \pm 65(4)$ & $83^{\star \star}$ \\
P7: & & & \\
Cochlear & $6210 \pm 140(4)$ & $652 \pm 89(4)$ & $95^{\star}$ \\
Vestibular & $4375 \pm 135(4)$ & $315 \pm 116(4)$ & $85^{\star}$ \\
\hline
\end{tabular}

${ }^{\mathrm{a}}$ Ganglionic neuron counts from 8 - $\mu \mathrm{m}$ serial sections and mean number of neurons $( \pm$ SEM) are shown. Number of samples is indicated in parentheses.

${ }^{\mathrm{b}}$ At each stage examined, number of neurons in the wild type was set to $100 \%$.

${ }^{\mathrm{c}}$ Statistical significance performed by Students $t$-test.

${ }^{\star} P<0.05$.

${ }^{\star \star} P<0.002$

In the BETA2/NeuroD1 null, we found clear defects even at the onset of CVG formation. First, there was a dramatic increase in the number of BETA2/NeuroD1positive cells within the null otic vesicle wall compared to heterozygous controls. As early as E9.5, there were more $\beta$-gal-positive cells within the null epithelium than within the heterozygous epithelium. Interestingly, in the heterozygous control, the CVG neuroblasts were more basal in the epithelium; while in the null, they were dispersed across the epithelium, from the apical (luminal) side to the base (Fig. 4, cf. a,c,e with b,d,f). By E11.5, the otocyst epithelium had few $\beta$-gal-positive cells in heterozygote (Fig. 4e) but numerous $\beta$-gal-positive cells in the null (Fig. 4f). This result suggests that there is a failure or delay of CVG neuroblasts to delaminate from the BETA2/NeuroD1 null otocyst.

Concurrent with the increased retention of $\beta$-gal-positive cells in the otocyst wall, there was a reduction of the size of the CVG complex at all stages of development. The large ball-shaped portion of the control CVG (cf. outlined CVG in Fig. 4c-f) was largely absent in the null. This population represents the differentiating or differentiated ganglion cells (mostly vestibular at E11.5). In the null, the neurons formed scattered clusters rather than the normal condensed ball morphology of the heterozygote ganglion (Fig. 4, cf. g and h). This phenomenon resembles the pancreatic islet phenotype found in the null (Naya et al. 1997); surviving islet cells fail to form a normal round-shaped mature islet but, instead, aggregate into small clusters. We speculate that a defect in cellcell interactions is the cause of this morphogenetic defect, but the molecules responsible have not been identified.

In the mouse, VG neurons are born between E9.5 and E12.5, with a peak in proliferation at E11.5, while CG neurons are born between E10.5 and E13.5 with peak production at E12.5 (Ruben 1967). As BETA2/NeuroD1 is expressed in the otic vesicle during the active proliferation period of CVG formation, we used BrdU staining and BrdU and $\beta$-gal double staining to examine whether the decrease in CVG neurons was the result of defective proliferation. The number of BrdU-labeled cells in the ventral otic epithelium and the forming CVG was largely similar between the null and control (outlined in Fig. $5 \mathrm{a}, \mathrm{b})$. This was confirmed by counting BrdU positive cells in double-stained ( $\beta$-gal and BrdU) sections (Fig. 5e). Thus, cell-fate determination and the proliferation steps during CVG development were largely unaffected in the null inner ear. Interestingly, BETA2/NeuroD1 was expressed in many dividing (BrdU-positive) cells during CVG formation (black arrows in Fig. 5c,d). The number of double-stained cells within the otocyst wall was higher in the null (Fig. 5d) than in heterozygotes (Fig. 5c). These data confirm that BETA2/NeuroD1 is expressed in some dividing cells as has been shown for the granule cells of the cerebellum and dentate gyrus (Miyata et al. 1999; Lee et al. 2000; Liu et al. 2000).

\section{Lack of trophic support and increased apoptosis contribute to the loss of CVG neurons}

The loss of CVG neurons in the BETA2/NeuroD1 null occurred up to E18.5 (Table 1), after which most residual neurons appeared to survive to adulthood. As described above, we propose that delay or failure of neuroblast precursor delamination from the otocyst causes the first wave of neuronal loss (E9.5-E12.5), but the magnitude and the timing of this defect can not completely account for the neuronal loss evident later on. Delamination of CVG neuroblasts was minimal in controls by E13.5, but CVG neuron loss continued, relative to the control, until E18.5 (Table 1). We therefore looked for additional effects of BETA2/NeuroD1 on CVG neuron number.

During normal development, pioneering afferent nerve fibers from the CVG first penetrate the vestibular epithelium at E12 and cochlear epithelium at E13, with a significant increase in the number of nerve fibers by E16 (Galinovic-Schwartz et al. 1991). Thus, the postdelamination reduction of CVG neurons in the null (E14-E18) occurs during target innervation. The survival and maintenance of CVG neurons depends on the neurotrophins BDNF and NT3 produced by the cochlear and vestibular epithelia. As null mutants for these proteins lose CG and VG neurons at late gestation (Ernfors et al. 1995), we therefore examined the effect of the BETA2/NeuroD1 null mutation on the expression of $\operatorname{Trk} B$, the receptor for the neurotrophins BDNF and NT3 (Pirvola et al. 1994). At E9, when the size of the null CVG was still comparable to the control, Trk $B$ expression was already greatly reduced in the null (Fig. 6A, see a,b). By E11.5, a large 
Liu et al.

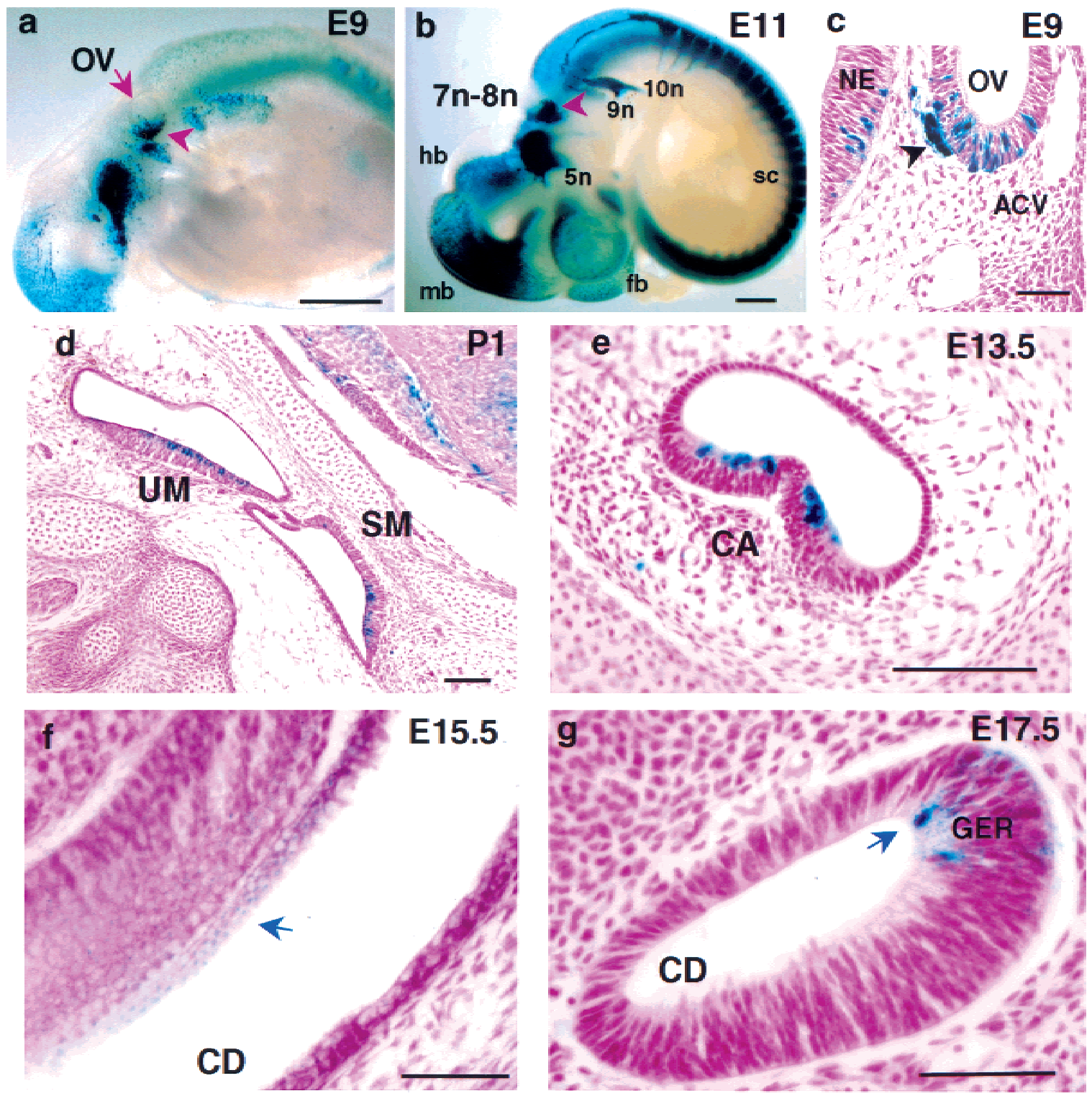

Figure 3. Expression of BETA2/NeuroD $1^{\text {lacz }}$ during ontogeny of the inner ear. BETA2/NeuroD $1^{\text {lacz }}$ heterozygote embryos from E9 to E17.5 and P1 inner ears were stained for $\beta$-gal activity as whole-mounts $(a, b)$ and sectioned $(8 \mu \mathrm{m}, c-g)$. Expression of BETA2/ NeuroD $1^{\text {lacZ }}$ can be seen in E9 embryos $(a$, scale bar $=100 \mu \mathrm{m})$ in the ventral side of the otic vesicle $($ ov, arrowhead) and at E11 $(b$, scale bar $=75 \mu \mathrm{m})$ in the VII-VIII nerve complex (7n-8n, arrowhead), the trigeminal (5n), petrosal (9n), and nodose (10n) nerves. At E11, expression is also prominent in: forebrain (fb), midbrain $(\mathrm{mb})$, hindbrain $(\mathrm{hb})$, and spinal cord (sc). (c) Cross section of the otic vesicle at E9 (scale bar $=100 \mu \mathrm{m}$ ) shows patches of expression in the ventral half, which subsequently gives rise to the CVG and cochlea. Note the BETA2/NeuroD1 $1^{\text {lacZ }}$ expression in the developing CVG (arrowhead). Expression is also observed within the sensory epithelial regions of the vestibule (sagittal section, $d$ : P1 scale bar $=200 \mu \mathrm{m})$, semicircular canals $(e:$ E13.5, scale bar $=300 \mu \mathrm{m})$ and cochlea $($ blue arrows, $f$ : E15.5, coronal section; $g$ : E17.5, sagittal section, scale bar in $f=100 \mu \mathrm{m}$, in $g=50 \mu \mathrm{m})$. NE, neuroepithelium; ACV, anterior cardinal vein; UM, utricular macula; SM, saccular macula; CA, cristae ampullaris; CD, cochlear duct; GER, greater epithelial ridge, an embryonic region for the future organ of Corti.

population of differentiating and TrkB-expressing CVG neurons was missing in the null (Fig. 6A, see e,f). According to the prevailing neurotrophic model, up to $25 \%$ of ganglion cells born will die during the competition for limited amounts of trophic factors (Ard et al. 1985). Therefore, we next sought to examine whether increased apoptosis contributes to the loss of CVG neurons in the BETA2/NeuroD1 null. Results obtained with the
TUNEL assay at E12 (Fig. 6B, see a,b) indicated that cell death was indeed dramatically increased (sixfold, $n=4$ ) in the delaminated and differentiating null CVG (arrowheads). Apoptosis was also increased within the ventral otic epithelium of the null relative to the control (arrowheads, Fig. 6B, see d). The elevated level of apoptosis in the null CVG was observed as early as E10 and persisted to E15 (data not shown). 

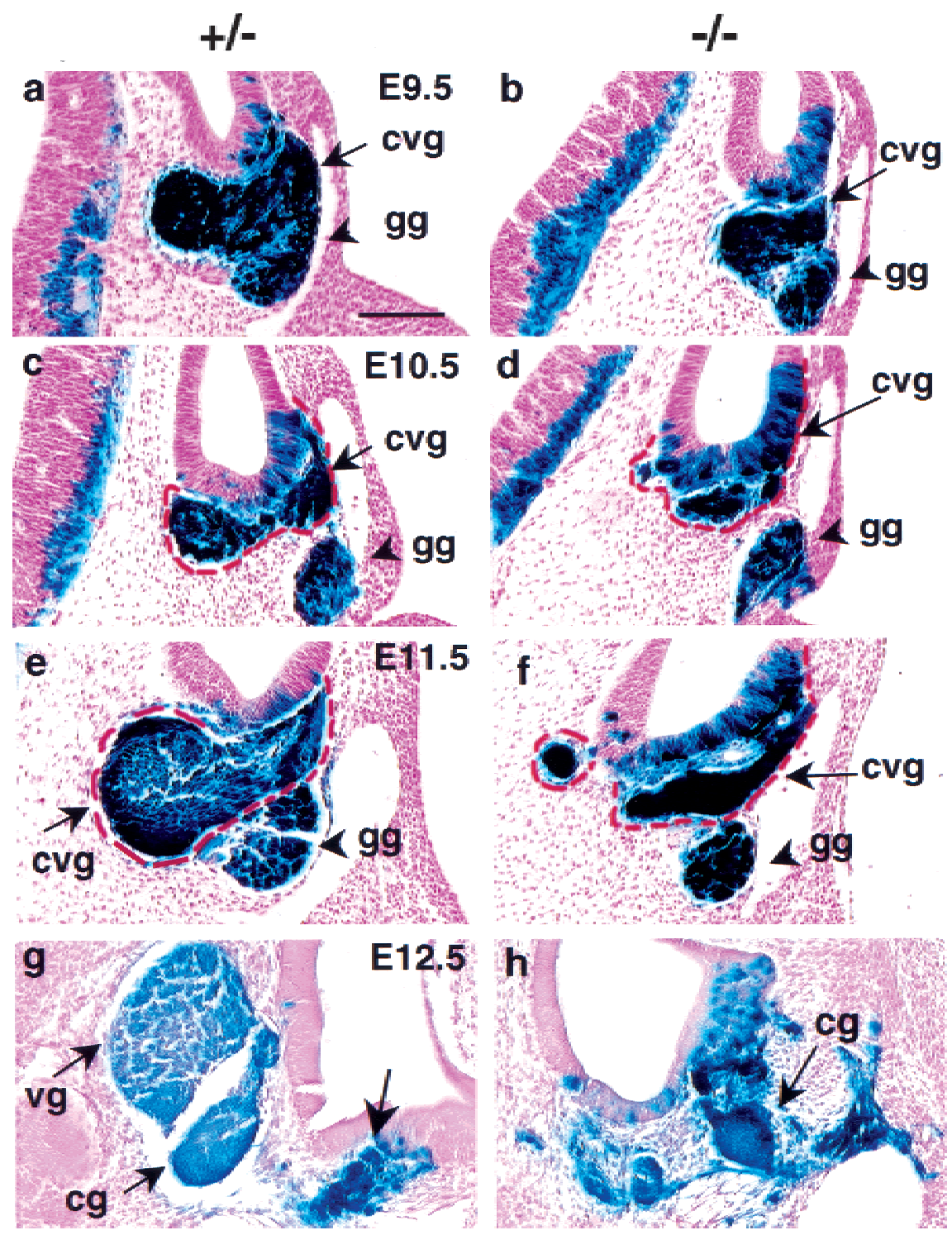

Figure 4. Failure/delay in CVG neuroblast delamination in the null otic vesicle. Early development of CVG neurons ( $\beta$-gal positive, arrow) in BETA2/NeuroD1 heterozygous $(a, c, e, g)$ and homozygous null $(b, d, f, h)$ from E9.5 to E12.5. As early as E9.5, there is an increase in CVG neuroblasts retained within the null otic epithelium compared to the controls (cf. $a, b)$. The retained CVG precursors in the nulls were located throughout the epithelium, from the apical (lumenal) side to the basal side. In contrast, in the heterozygous animals, the blue CVG precursors are located more toward the base of the epithelium, where they are readily engaged to delaminate. This failure/delay in delamination became more severe during the subsequent peak period of CVG formation (E10.5-E12.5). By E10.5 and E11.5, the forming CVG is obviously reduced in size in the null compared to the control $/ \mathrm{com}$ pare red outlines of CVG in $c-h$ ). At E12.5, the residual CVG neurons formed scattered clusters $(h)$ rather than the compact ganglion complex seen in the control $(g)$. Note that the geniculate ganglion $(\mathrm{gg}$, arrowheads in $a-f$ ) near the head vein (n.VII, facial ganglion, spherical shape) is unaffected in the null (scale bar $100 \mu \mathrm{m})$.
Given the essential roles of neurotrophins and their receptors in the survival, growth, and differentiation of CVG neurons (Fritzsch et al. 1997), it is expected that a decreased level of $\operatorname{Trk} B$ would produce a smaller CVG. However, the decreased $\operatorname{Trk} B$ expression level and apoptosis in the BETA2/NeuroD1 null occurred earlier than the times at which deficits are first seen in mice that are null for TrkB or for BDNF and NT3 (E16; Schimmang et al. 1995; Ernfors et al. 1995). Therefore, there may be other factor(s) downstream of BETA2/NeuroD1 that act earlier than TrkB (between E10 and E15) to regulate the initial survival and maintenance of CVG neurons.

\section{Shortening of the cochlear duct}

Paint-filled membranous labyrinths from the BETA2/ NeuroD1 null revealed a significantly shortened co- chlear duct but otherwise normal labyrinth morphology (Fig. 7). The cochlear duct develops as an extension of the ventral part of the otic vesicle, beginning around E12. The increase in length of the proximal portion (the hook) of the cochlear duct occurs concurrently with the coiling of the distal portion (the coil). At E13.5, the snail-shaped duct normally consists of approximately one turn. In the BETA2/NeuroD1 null, there was no difference in length compared to the control, but the null distal coil turned more acutely (white arrows in Fig. 7b,d). Two days later, the control cochlear duct had grown to one and a quarter turns, while the null duct was still just a bit over one turn in length and was appreciably thicker than the control duct (double arrowheads Fig. 7c,d). The null duct failed to grow any more, while the control duct continued to grow, reaching its mature form by E17 (data not shown). The reduced coiling in the null cochlea could also be seen in the cochlea sectioned at the midmodiolar level at $1 \mathrm{mo}$ of age (Fig. 2c,d). 
Liu et al.

Figure 5. Proliferation of CVG is largely unaffected in BETA2/NeuroD1 null. $(a, b)$ Proliferative activity, revealed by BrdU immunohistochemistry on cross sections at E11, is high in the otic epithelium, forming CVG and the surrounding mesenchyme. The BrdU-positive cells in the forming CVG, including those within the ventral otic epithelium, are comparable in number between the control and the null (as outlined in $a, b$, scale bar $=300 \mu \mathrm{m}$ ). In the control $(a)$, the mitotic figures are found only on the edge of the CVG but not within the CVG itself. However, in the null mutant $(b)$, the mitotic figures are found both on the edge of and within the forming CVG. $(c, d)$ BrdU and $\beta$-gal double labeling at E12 shows that BETA2/NeuroD1 is also found in mitotic cells. Approximately one-third of the BETA2/NeuroD1-positive cells within the null otic wall are also BrdU positive, while about one-tenth of those within the control otic wall are also BrdU positive. BETA2/NeuroD1 and BrdU double-positive, black arrow; BETA2/NeuroD1 positive, blue arrow; BrdU positive: orange arrow; scale bar in $c-d=400 \mu \mathrm{m}$, and insert $=200 \mu \mathrm{m}$. $(e)$ Sum of BrdU positive cell numbers in the forming CVG at E10.5, E11.5, and E12.5. Mean numbers \pm S.D. are shown $(n=2-3$ embryos in each group). BrdU detection was performed on X-gal stained sections to help define the CVG region. Cells in the otic epithelium and forming CVG were counted.

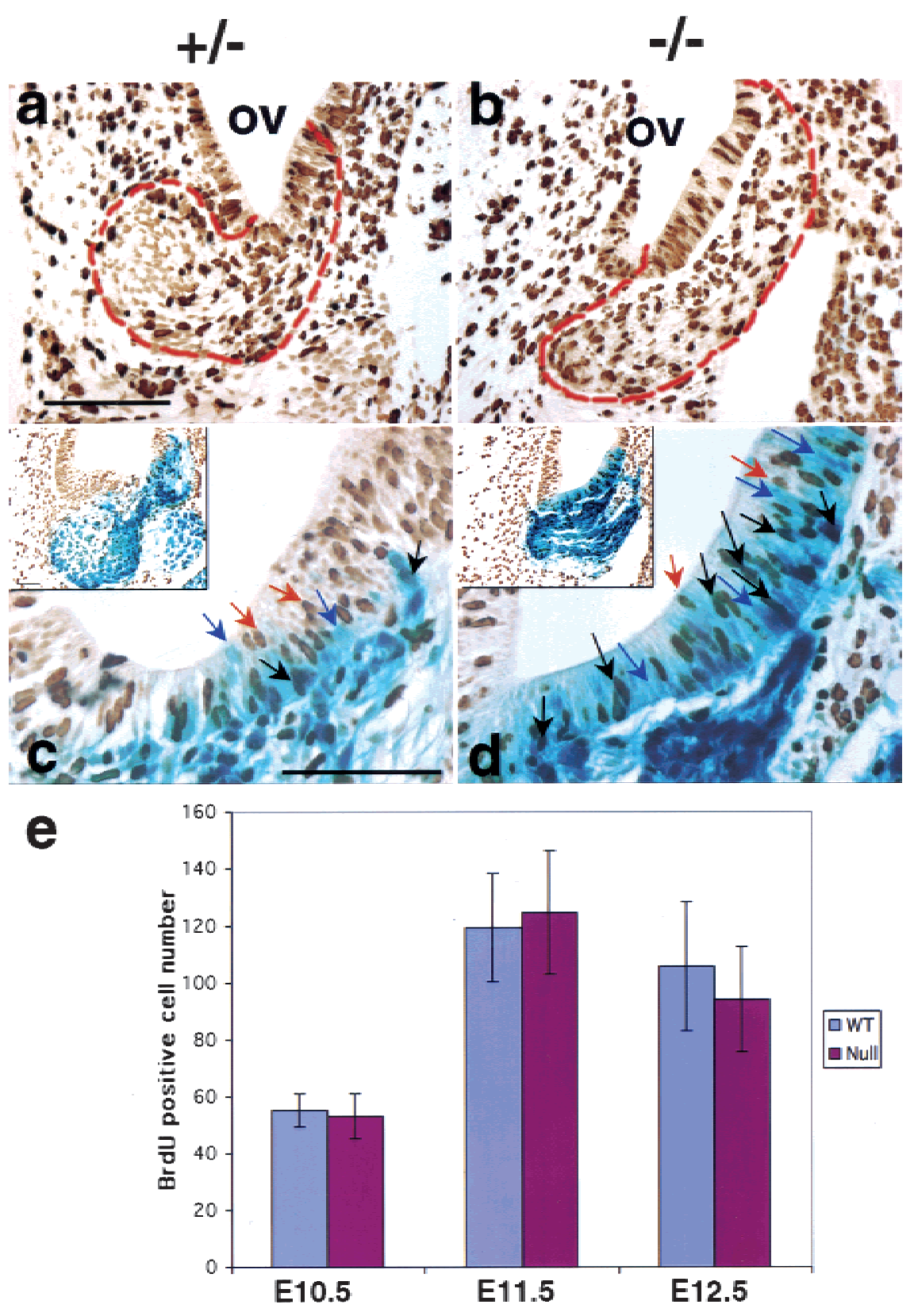

\section{Defects in the CVG targets}

Loss of central nuclei and atrophy of eighth nerve fibers in the brainstem Cochlear and vestibular neurons are bipolar with a short peripheral process contacting the hair cell mechanoreceptors in their respective sensory epithelia and a long central process projecting to the cochlear and vestibular nuclei within the medulla. The axons of the CG leave the base of the cochlea, join with the vestibular fibers, and enter the posterior cranial fossa accompanied by the facial nerve. These primary sensory neurons terminate in the dorsal and ventral cochlear nuclei at the junction of the brainstem and medulla. The dorsal cochlear nucleus (DCN) forms a small bump, the acoustic tubercle, in the brainstem. The acoustic tubercle was missing in mutant mice (Fig. 8a,b). It is possible that the loss of the majority of CG neurons resulted in a loss of innervation and lead to problems in the central targets of these neurons. In addition, as BETA2/NeuroD1 is expressed in the cochlear and vestibular nuclei during embryonic development (data not shown), the null mutation may directly affect the formation of these nuclei. Cresyl violet staining (Fig. 8c,d) confirms the lack of the DCN in the null. Moreover, the eighth nerve fiber bundle connecting the brainstem and inner ear, which includes the central processes of the CG and VG neurons and efferent nerve fibers, was also drastically reduced and/or missing in the null (Fig 8e,f). 








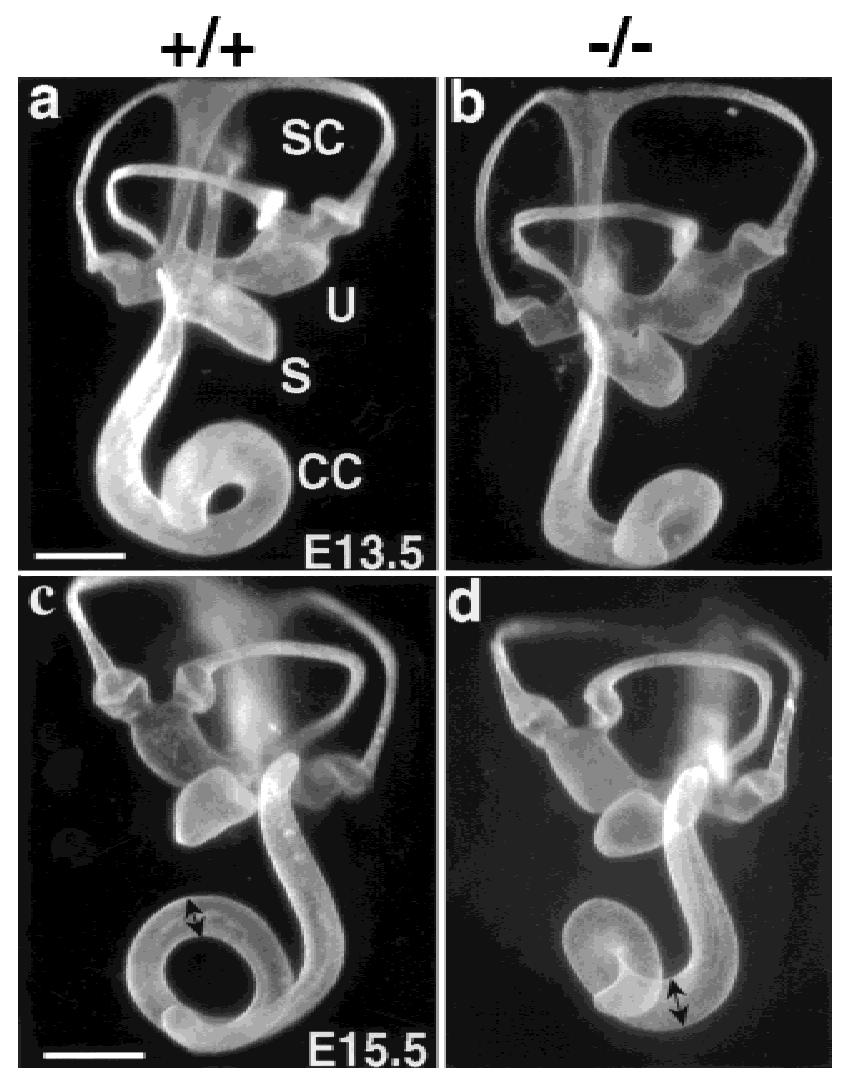

Figure 7. The null cochlear duct is shortened. Lateral view of paint-filled membranous labyrinths at E13.5 $(a, b$, scale bar $=150 \mu \mathrm{m})$ and E15.5 $(c, d$, scale bar $=250 \mu \mathrm{m})$. At E13.5, the null and normal duct coils are both one and one-quarter turns. By E15.5, however, the control cochlear duct reaches greater than one and one-half turns, while the null duct shows no further growth in length but seems thicker than the control (cf. black double arrowheads in $c, d)$. Note that the endolymphatic duct is present but poorly filled with paint in the null.

\section{Ultrastructural defects in the peripheral targets of CVG}

$\beta$-gal staining (Fig. 3d-g) revealed that BETA2/NeuroD1 is expressed in the prospective sensory epithelia. Thus, the cochlear and vestibular sensory epithelia of the wild type and null were examined using scanning electron microscopy (SEM) and light microscopy (LM) of semithin sections. In the normal organ of Corti, outer hair cells (OHC) are arranged in three rows and inner hair cells (IHC) are in a single row extending the length of the cochlear duct. Semithin sections of null temporal bones revealed OHCs and IHCs, as in the control (Fig. 2e,f). This is consistent with the view that the CVG is not required for the cytodifferentiation of inner ear sensory receptors (Jorgensen and Flock 1976; Rüsch et al. 1998b). However, SEM revealed misalignments and misplacements of the cochlear hair cells (Fig. 9a,b). In the wild type, hair bundles are oriented radially with respect to the cochlear spiral, while in many places along the null cochlear duct, some OHCs were turned at $45^{\circ}, 60^{\circ}$, or even $90^{\circ}$ relative to the others. In some regions, there were four rows of OHCs instead of the usual three. In addition, ectopic IHCs were found scattered among the first row of OHCs. Even more striking was the presence of two rows of IHCs rather than the usual single row (white arrowhead in Fig. 9b). The hair bundles in the null OHCs and IHCs appear normal (see insert in Fig. 9b).

The vestibular epithelia contain two types of receptor cells: The flask-shaped type I hair cells surrounded by a cup-shaped nerve ending (calyx), and the more cylindrical type II hair cells that receive multiple bouton-type afferent endings. In the null epithelia at 3 mo of age (Fig. $9 \mathrm{~d}, \mathrm{f})$, both hair cell types were present. This is consistent with results from mice null for neurotrophins and their receptors, which, despite the loss of afferent innervation, have epithelia that appear normal (Minichiello et al. 1995; Schimmang et al. 1995; Silos-Santiago et al. 1997). In the vestibular epithelia of the BETA2/NeuroD1 null, most afferent fibers were missing, as expected from the drastically reduced VG. However, at least in the saccular macula (Fig. 9d), some afferent nerve fibers persisted, principally in a cytoarchitectonically and physiologically distinct region called the striola. Taken together, our data show that at 3 mo of age, some ganglion cells and their peripheral processes persist but that, at least in some cases, there are no central processes into the brainstem of the BETA2/NeuroD1 null.

\section{Discussion}

The mammalian inner ear contains very sophisticated mechanosensory elements and a highly specific set of neuronal connections for the transduction of mechanical energy to electrical impulses in the cochlear and vestibular nerve. Many factors are required for regulating its development. Our results show that BETA2/NeuroD1 is essential for the formation of cochlear and vestibular ganglion neurons. At an early stage, BETA2/NeuroD1 is already prominently expressed in the otic vesicle, the delaminating neuroblasts, and the forming ganglia. Importantly, its expression is found not only in the differentiated neurons but also in the dividing neurons. This is of special interest as, until recently, it had been generally believed that BETA2/NeuroD1 was only expressed in postmitotic/differentiating cells (Miyata et al. 1999; Lee et al. 2000; Liu et al. 2000). Our data indicate that lack of BETA2/NeuroD1 caused retention of a large population of neuroblast precursors within the otocyst. One explanation for our observation is that BETA2/NeuroD1 is required in the neuroblast precursors in the last round of cell division to promote cell cycle exit and to initiate differentiation. Similarly, in the case of enteroendocrine cells, it has been suggested that BETA2/NeuroD1 acts together with the coactivator p300 to induce the expression of p21, a cyclin-dependent cell cycle inhibitor $(\mathrm{Mu}-$ toh et al. 1998). If this were the case in the otic epithelium, one might expect enhanced proliferation. We saw no difference in proliferation between null and wild-type epithelia with a single BrdU labeling period of $1.5 \mathrm{~h}$; however, for this question to be examined fully, a pulsechase BrdU study should be performed. An alternative 




Figure 8. Absence of the dorsal cochlear nucleus (DCN) and eighth nerve in the null. $(a, b)$ Ventral view of whole-mount $\beta$-gal stained heterozygous $(a)$ and null $(b)$ brains at 6 wk of age. Note that $\mathrm{n}$.VIII (see bracket in $a$, arrowhead in $b$ ) and the small bump representing the whole population of the DCN are missing in the null ( ${ }^{*}$ in $a, b$; scale bar $\left.=200 \mu \mathrm{m}\right)$. This loss is confirmed by cresyl violet-stained

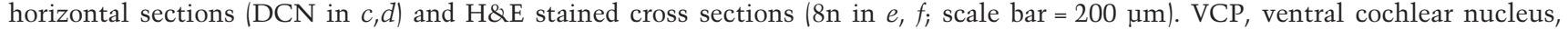
posterior; vg: vestibular ganglion; 8vn, vestibular nerve root; sp5, spinal tract of Vth cranial nerve; Tn, nucleus of sp5; cb, cerebellum; $\mathrm{cp}$, choroid plexus.

hypothesis is that lack of BETA2/NeuroD1 in the neuroblast precursors resulted in failure of these cells to initiate differentiation, thus retarding delamination. Thus, although the initial cell fate determination and proliferation of CVG neurons appeared to be largely unaffected in the null, BETA2/NeuroD1 is required for CVG delamination and differentiation.

The TrkB-labeling experiments revealed another form of altered differentiation. Down-regulation of neurotrophin receptors such as TrkB in the BETA2/NeuroD1 null is expected to compromise CVG maturation and survival. In mice lacking the neurotrophins and/or their receptors, CVG neurons are born, but in NT-3 and TrkC null mice, most cochlear neurons degenerate later in gestation. In the BDNF and TrkB null mice, most of the developing vestibular neurons are lost at mid- to late gestation (Fritzsch et al. 1997). In contrast, the CVG deficit in the BETA2/NeuroD1 null occurs earlier during ontogenesis of these ganglia. This suggests that there must be other growth factors, downstream targets of BETA2/ 
Liu et al.
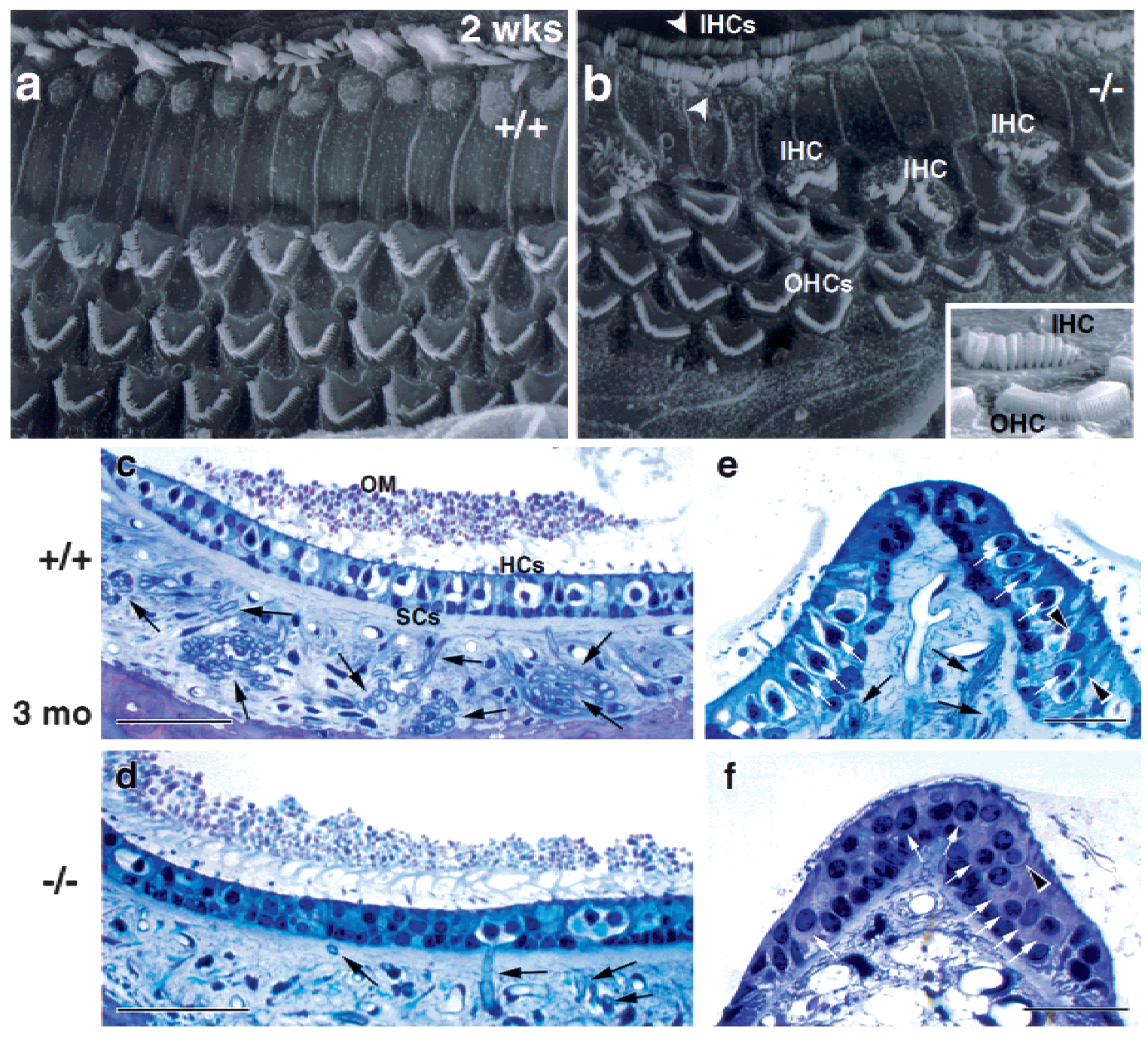

Figure 9. Sensory epithelia defects in the null organ of Corti. $(a, b)$ Scanning electron micrographs of the organ of Corti in wild type and null. The surface of the wild type organ of Corti $(a)$ shows the orderly pattern of three rows of OHCs and one row of IHCs. The null organ of Corti (b) shows misalignment and additional OHCs and duplication of IHCs (arrowheads in $b$, scale bar in $a-b=1 \mu \mathrm{m}$ ). In addition, many ectopic IHCs are located amongst the first row of OHCs; the two cell types are readily distinguished by their hair bundles (see insert in $b$, scale bar $=2 \mu \mathrm{m}) .(c-f)$ Semithin sections of the sensory epithelium in otolith organs $(c, d$, scale bar $=50 \mu \mathrm{m})$ and cristae $(e, f$, scale bar $=25 \mu \mathrm{m})$ of 3-mo-old mice. In the sensory epithelia of both the null saccule and crista, hair cells are present (white arrows in $e, f$ ). While some afferents persist in the null saccular macula (black arrows in $d$ ), the number of nerve fibers is greatly reduced $(d, f)$. The two morphologically distinguishable types of vestibular hair cells are present in the null. Type I hair cells are vase shaped and surrounded by an afferent nerve chalice (light spherical or ovoid profiles in $c, e$; see white arrows in $e$ ) as shown for the null saccular macula $(d)$. In the null crista, no afferents are evident and therefore no nerve chalices, but vase-shaped cells are seen (arrowhead in f). Type II cells, which receive bouton afferent endings, are also present in the null (arrowheads in $e$ ). HCs, hair cells; SCs, supporting cells; OM, otolithic membrane.

NeuroD1, that are required at the early stage of CVG development. This does not mean that TrkB does not have an effect at the earlier stages of CVG development but may play a role in combination with these other growth factors. In addition, the initial CVG afferent contacts with their targets, which are a prerequisite for neurotrophic action, may have been reduced during the first wave of ganglion neuron loss (E9.5-E12.5). However, whether the sensory epithelia are defective in providing neurotrophic support is one possibility that remains to be examined.
There are other gene-targeted mouse models in which CVG neurons are decreased or lost. Neurogenin 1 (ngn1), acting as a proneural cell fate determination gene, is a positive upstream regulator of BETA2/NeuroD1. Mouse embryos lacking ngn1 fail to generate the proximal subset of cranial sensory neurons, including those in the CG and VG, as a result of defective cell fate determination of CVG neuronal precursors (Ma et al. 1998). Neurogenin3 (ngn3) is also an upstream regulator of BETA2/NeuroD1 (Huang et al. 2000; Gradwohl et al. 2000). Thus, the question remains as to what extent the phenotypes iden- 
tified in the neurogenin null mice result from the loss of BETA2/NeuroD1 function.

The BETA2/NeuroD1 null has an unusually short and widened cochlear duct. The oldest part of the organ of Corti appears at the apex, while the youngest is at the base (Ruben 1967). Whether this shortening of the null cochlear duct is a direct or indirect effect of the null mutation is unclear. One possibility is that growth factor(s) that regulate cell proliferation in the inner ear are down-regulated in the BETA2/NeuroD1 null ear. In vitro explant studies have shown that IGF-1 is a potent growth-promoting and survival factor for otic vesicle development (Oesterle et al. 1997). Consistent with the down-regulation of $\operatorname{Trk} B$, a maintenance and survival factor for neurons in the null, growth-promoting genes like $I G F-1$ may be candidate downstream targets of BETA2/NeuroD1 in the ear.

The analysis of the BETA2/NeuroD1 null ears revealed some defects in hair cell organization in the organ of Corti, including duplication of, and ectopic addition of, IHCs and misalignment of OHCs. Increased numbers of hair cells were also seen in mice with null mutations for Jagged 2, a Notch 1 ligand (Lanford et al. 1999), and p27 Kip1, a cell cycle inhibitor (Chen and Segil 1999). In the Jagged 2 null, the mechanism is a cell fate switch from supporting cell to hair cell, as a result of decreased Notch-mediated lateral inhibition. In the $p 27^{\text {Kip } 1}$ null, hyperplasia of both IHCs and OHCs results from the loss of control of cell cycle progression. Because BETA2/NeuroD1 is believed to promote exit from the cell cycle, its absence in the null may explain the presence of ectopic and duplicated IHCs. Excess numbers of IHCs could secondarily lead to misalignment of OHCs. Alternatively, the abnormal retention of CVG neuroblast precursors in the null otic epithelia may have affected the organization of the developing hair cells.

This study has found several important contributors to the hearing loss documented by $\mathrm{ABR}$ testing in the BETA2/NeuroD1 null: The severe depletion of CG neurons and at least one central target (the DCN), shortening of the cochlear duct, and abnormalities within the organ of Corti. It is interesting that heterozygous mice showed a higher ABR threshold when compared with the wild type. Recently, mutations of BETA2/NeuroD1 were implicated in the development of familial human type II diabetes in the heterozygous state (Malecki et al. 1999). The ABR test might be useful for screening diabetic patients for possible BETA2/NeuroD1 mutations, allowing a better correlation of hearing impairment and diabetes.

The BETA2/NeuroD1 null also showed defective balance behaviors. Balance depends on complex interactions of sensory and motor systems. The atrophy of the VG shown in this study contributes to the imbalance in the null, but any defects in the central vestibular system or the motor system could also be factors. BETA2/NeuroD1 is also expressed in spinal cord, vestibular nuclei, and cerebellar granule cells (Miyata et al. 1999; Lee et al. 2000; Liu et al. 2000). Central processes of VG neurons form the vestibular division of the eighth nerve, which terminates in the vestibular nuclear complex in the floor of the fourth ventricle. In addition, a small number of these axons terminate in the flocculonodular lobe of the cerebellum. The medial and inferior vestibular nuclei have reciprocal connections with the cerebellum (vestibulocerebellar tract) that allow the cerebellum to coordinate balance during movement. We (M. Liu and M.J.Tsai, unpubl.) and others (Miyata et al. 1999) have found that the posterior part of the cerebellum, including the vestibulocerebellum (lobule X), is more severely affected (loss of granule cells) than the anterior cerebellum in the null brain. This might in part be secondary to the loss of the VG, or vice versa, or caused by a mutual loss. The degree and mechanism of involvement of the CNS component in the manifestation of the phenotype is unclear and under investigation.

In summary, lack of BETA2/NeuroD1 causes a severe loss of CVG neurons, loss of the DCN, and alterations in the mechanosensory hair cells and structural components of the inner ear. Thus, BETA2/NeuroD1 is the first gene in which mutations produce both neuronal and sensory defects in both vestibular and cochlear organs. Moreover, this gene acts centrally in both systems: Its loss eliminates the DCN and the granule cells of the posterior cerebellum. This is the first molecular evidence that a specific gene has evolved to regulate critical developmental events such as balance in functionally related parts of the mammalian peripheral and central nervous systems.

\section{Materials and methods}

Animals

BETA2/NeuroD1 null mice were generated in the $129 /$ SvJ background as described (Liu et al. 2000).

\section{Auditory Brainstem Response (ABR)}

ABR was recorded at $10 \mathrm{wk}$ of age to assess hearing abilities. Mice were anesthetized with $45 \mathrm{mg}$ Ketamine $/ \mathrm{kg}$ and $5.4 \mathrm{mg}$ xylazine $/ \mathrm{kg}$. Electrodes were placed at the vertex (active) and behind the ear (reference). Tucker-Davis Technology software and hardware was used to generate the stimulus and collect ABR data. Pulses $5 \mathrm{msec}$ long were presented at a rate of 20/sec to a speaker (Entymotic ER-2). Intensity levels are given in $\mathrm{dB}$ re 0.001 volts (RMS) into the speaker, and were presented from 100 to $25 \mathrm{~dB}$ in $5-\mathrm{dB}$ decrements. At each intensity, 500 responses were averaged. Threshold is defined as the level at which wave 2 disappeared.

\section{Tissue processing and neuron counting}

E9-E12 embryos or heads (E13-P8) were collected and fixed in $4 \%$ paraformaldehyde in PBS at $4^{\circ} \mathrm{C}$ for periods between $6 \mathrm{~h}$ and overnight. The older animals were anesthetized with avertin $(150 \mathrm{mg} / \mathrm{kg})$ and transcardially perfused. Inner ears were dissected from postnatal heads, fixed overnight, decalcified with $10 \%$ formic acid for $4 \mathrm{~d}$ at room temperature, and then processed for paraffin embedding. Neuron counts were done on serial 8 - $\mu \mathrm{m}$ sections stained either with $0.5 \%$ cresyl violet or hematoxylin and eosin (H\&E). Neurons with a clear nucleus 
and nucleoli were counted in every fifth section. Counts were not corrected for double or split nucleoli.

\section{Paint-filling}

Inner ears were excised from staged wild-type and null embryos, fixed in Bodian's fixative, dehydrated in ethanols, and cleared in methyl salicylate. The membranous labyrinths were visualized using latex paint injections as previously described (Morsli et al. 1999). At least two pairs of inner ears were injected for each stage presented.

\section{Semithin sections and electron microscopy}

Semithin sectioning and staining was carried out as described previously (Lysakowski and Goldberg 1997). Briefly, wild-type and null littermates at $2 \mathrm{wk}$ and 3 mo of age were anesthetized with avertin $(150 \mathrm{mg} / \mathrm{kg}$ body weight $)$ and perfused transcardially with $30 \mathrm{~mL}$ of a warm $0.1 \mathrm{M}$ sodium cacodylate $0.9 \% \mathrm{NaCl}$ buffer (pH 7.4), followed by $100 \mathrm{~mL}$ of a warm trialdehyde fixative, consisting of $3 \%$ glutaraldehyde, $2 \%$ paraformaldehyde, $1 \%$ Acrolein, and $5 \%$ sucrose in $0.08 \mathrm{M}$ cacodylate buffer (DeGroot et al. 1987). Temporal bones were dissected, postfixed for $1 \mathrm{~h}$ in either $1 \% \mathrm{OsO}_{4}$ in $0.1 \mathrm{M}$ cacodylate buffer, decalcified in Cal-Ex for 1-2 h, dehydrated in graded ethanol and propylene oxide, and embedded in Araldite (Durcupan). Temporal bones were sectioned in the horizontal plane. Serial sections, $4 \mu \mathrm{m}$ thick, were cut with a diamond knife through the whole temporal bone, mounted on glass slides, and stained with Richardson's stain. Hair cells and supporting cells were classified using morphological criteria developed previously (Rüsch et al. 1998b). Tissue preparation for SEM consisted of osmication (1\% $\mathrm{OsO}_{4}$ in cacodylate buffer), dehydration, critical-point drying, and sputter-coating with gold. Specimens were examined in a JEOL 35 S electron microscope.

ß-gal activity staining, in situ hybridization, and immunohistochemistry

Embryos were isolated and prepared for double-labeling with $\mathrm{X}$-Gal and BrdU antibody as previously described (Liu et at. 2000) on 8- $\mu \mathrm{m}$ serial cross sections. BrdU (Amersham Life Science, RPN 201) was injected intra-peritoneally. $1 \mathrm{~h}$ before sacrifice at $150 \mu \mathrm{g} / \mathrm{g}$ body weight. In situ hybridization was performed as described (Qiu et al. 1994) using a TrkB antisense RNA probe (Klein et al. 1990). At least three animals were analyzed at each stage. Animals were treated according to animal care guidelines at Baylor College of Medicine and the University of Illinois at Chicago.

\section{Acknowledgments}

We thank Samuel Pleasure, Cheng Zhou, and Norio Takamoto for helpful advice and discussion and M. Barbacid for the TrkB cDNA plasmid. We also thank Bobby Antalffy, Jing $\mathrm{Xu}$, and Jiwen Li for technical assistance. M.L. is supported by a National Research Service Award fellowship from National Institute of Diabetes and Digestive and Kidney Disease. This work was supported by grants from the NIH to M.-J. T. and from the National Institute of Deafness and Other Communication Disorders to W.B. (DC-02775), F.A.P. (DC-04585), and R.A.E. and A.L. (DC-02290).

The publication costs of this article were defrayed in part by payment of page charges. This article must therefore be hereby marked "advertisement" in accordance with 18 USC section 1734 solely to indicate this fact.

\section{References}

Altman, J. and Bayer, S.A. 1982. Development of the cranial nerve ganglia and related nuclei in the rat. Adv. Anat. Embryol. Cell Biol. 74: 1-90.

Anniko, M. 1983. Early development and maturation of the spiral ganglion. Acta Otolaryngol. 95: 263-276.

Anniko, M. and Wikstrom, S.O. 1984. Pattern formation of the otic placode and morphogenesis of the otocyst. Am. J. Otolaryngol. 5: 373-381.

Ard, M.D., Morest, D.K., and Hauger, S.H. 1985. Trophic interactions between the cochleovestibular ganglion of the chick embryo and its synaptic targets in culture. Neuroscience 16: $151-170$.

Bermingham, N.A., Hassan, B.A., Price, S.D., Vollrath, M.A., Ben-Arie, N., Eatock, R.A., Bellen, H.J., Lysakowski, A., and Zoghbi, H.Y. 1999. Math1: An essential gene for the generation of inner ear hair cells. Science 284: 1837-1841.

Bianchi, L.M., Conover, J.C., Fritzsch, B., DeChiara, T., Lindsay, R.M., and Yancopoulos, G.D. 1996. Degeneration of vestibular neurons in late embryogenesis of both heterozygous and homozygous BDNF null mutant mice. Development 122: $1965-1973$.

Bissonnette, J.P. and Fekete, D.M. 1996. Standard atlas of the gross anatomy of the developing inner ear of the chicken. J. Comp. Neurol. 368: 620-630.

Bussoli, T.J., Kelly, A., and Steel, K.P. 1997. Localization of the bronx waltzer (bv) deafness gene to mouse chromosome 5 . Mamm. Genome 8: 714-717.

Chen, P. and Segil, N. 1999. p27(Kip1) links cell proliferation to morphogenesis in the developing organ of Corti. Development 126: 1581-1590.

Chisaka, O., Musci, T.S., and Capecchi, M.R. 1992. Developmental defects of the ear, cranial nerves and hindbrain resulting from targeted disruption of the mouse homeobox gene Hox-1.6. Nature 355: 516-520.

Crawley, J.N. and Paylor, R. 1997. A proposed test battery and constellations of specific behavioral paradigms to investigate the behavioral phenotypes of transgenic and knockout mice. Horm. Behav. 31: 197-211.

D'Amico-Martel, A. and Noden, D.M. 1983. Contributions of placodal and neural crest cells to avian cranial peripheral ganglia. Am. J. Anat. 166: 445-468.

deGroot, J.C., Veldman, J.E., and Huizing, E.H. 1987. An improved fixation method for guinea pig cochlear tissues. Acta Oto-Laryngol. 104: 234-242.

Erkman, L., McEvilly, R.J., Luo, L., Ryan, A.K., Hooshmand, F., O'Connell, S.M., Keithley, E.M., Rapaport, D.H., Ryan, A.F., and Rosenfeld, M.G. 1996. Role of transcription factors Brn3.1 and Brn-3.2 in auditory and visual system development. Nature 381: 603-606.

Ernfors, P., Van De Water, T., Loring, J., and Jaenisch, R. 1995. Complementary roles of BDNF and NT-3 in vestibular and auditory development. Neuron 14: 1153-1164.

Farinas, I. and Reichardt L.F. 1996. Neurotrophic factors and their receptors: Implications of genetic studies. Neurosciences 8: 133-143.

Fekete, D.M. 1996. Cell fate specification in the inner ear. Curr. Opin. Neurobiol. 6: 533-541.

Fritzsch, B., Silos-Santiago, I., Bianchi, L.M., and Farinas, I. 1997. The role of neurotrophic factors in regulating the development of inner ear innervation. Trends Neurosci. 
20: $159-164$.

Galinovic-Schwartz, V., Peng, D., Chiu, F.C., and Van de Water, T.R. 1991. Temporal pattern of innervation in the developing mouse inner ear: An immunocytochemical study of a $66-\mathrm{kD}$ subunit of mammalian neurofilaments. J. Neurosci. Res. 30: 124-133.

Gibson, F., Walsh, J., Mburu, P., Varela, A., Brown, K.A., Antonio, M., Beisel, K.W., Steel, K.P., and Brown, S.D. 1995. A type VII myosin encoded by the mouse deafness gene shaker1. Nature 374: 62-64.

Gradwohl, G., Dierich, A., LeMeur, M., and Guillemot, F. 2000. neurogenin 3 is required for the development of the four endocrine cell lineages of the pancreas. Proc. Natl. Acad. Sci. 97: 1607-1611.

Hadrys, T., Braun, T., Rinkwitz-Brandt, S., Arnold, H.H., and Bober, E. 1998. Nkx5-1 controls semicircular canal formation in the mouse inner ear. Development 125: 33-39.

Hemond, S.G. and Morest, D.K. 1991. Ganglion formation from the otic placode and the otic crest in the chick embryo: Mitosis, migration, and the basal lamina. Anat. Embryol. 184: $1-13$.

Holme, R.H. and Steel, K.P. 1999. Genes involved in deafness. Curr. Opin. Genet. Dev. 9: 309-314.

Huang, H.P., Liu, M., El-Hodiri, H.M., Chu, K., Jamrich, M., and Tsai, M.J. 2000. Regulation of the pancreatic islet-specific gene BETA2 (neuroD) by neurogenin 3. Mol. Cell Biol. 20: $3292-307$

Jacobson, A.G. 1963. The determination and positioning of the nose, lens and ear. J. Exp. Zool. 154: 273-303

Jan, Y.N. and Jan, L.Y. 1993. HLH proteins, fly neurogenesis, and vertebrate myogenesis. Cell 75: 827-830.

Jorgensen, J.M. and Flock, A. 1976. Non-innervated sense organs of the lateral line: Development in the regenerating tail of the salamander Ambystoma mexicanum. J. Neurocytol. 5: $33-41$.

Klein, R., Conway, D., Parada, L.F., and Barbacid, M. 1990. The trkB tyrosine protein kinase gene codes for a second neurogenic receptor that lacks the catalytic kinase domain. Cell 61: 647-656.

Kubisch, C., Schroeder, B.C., Friedrich, T.B., Lutjohann, ElAmraoui, A., Marlin, S., Petit, C., and Jentsch, T.J. 1999. KCNQ4, a novel potassium channel expressed in sensory outer hair cells, is mutated in dominant deafness. Cell 96: 437-446.

Lanford, P.J., Lan, Y., Jiang, R., Lindsell, C., Weinmaster, G., Gridley, T., and Kelley, M.W. 1999. Notch signalling pathway mediates hair cell development in mammalian cochlea. Nat. Genet. 21: 289-292.

Lee, J.E., Hollenberg, S.M., Snider, L., Turner, D.L., Lipnick, N., and Weintraub, H. 1995. Conversion of Xenopus ectoderm into neurons by NeuroD, a basic helix-loop-helix protein. Science 268: 836-844.

Lee, J.K., Cho, J.H., Hwang, W.S., Lee, Y.D., Reu, D.S., and SuhKim, H. 2000. Expression of neuroD/BETA2 in mitotic and postmitotic neuronal cells during the development of nervous system. Dev. Dyn. 217: 361-367.

Li, C.W., Van De Water, T.R., and Ruben, R.J. 1978. The fate mapping of the eleventh and twelfth day mouse otocyst: An in vitro study of the sites of origin of the embryonic inner ear sensory structures. J. Morphol. 157: 249-267.

Liu, M., Pleasure, S.J., Collins, A.E., Noebels, J.L., Naya, F.J., Tsai, M.J., and Lowenstein, D.H. 2000. Loss of BETA2/NeuroD leads to malformation of the dentate gyrus and epilepsy. Proc. Nat1. Acad. Sci. 97: 865-870.

Lohnes, D., Mark, M., Mendelsohn, C., Dolle, P., Dierich, A., Gorry, P., Gansmuller, A., and Chambon, P. 1994. Function of the retinoic acid receptors (RARs) during development (I): Craniofacial and skeletal abnormalities in RAR double mutants. Development 120: 2723-2748.

Lysakowski, A. and Goldberg, J.M. 1997. A regional ultrastructural analysis of the cellular and synaptic architecture in the chinchilla cristae ampullares. J. Comp. Neurol. 389: 419443.

Ma, Q., Chen, Z., del Barco Barrantes, I., de la Pompa, J.L., and Anderson, D.J. 1998. neurogenin 1 is essential for the determination of neuronal precursors for proximal cranial sensory ganglia. Neuron 20: 469-482.

Malecki, M.T., Jhala, U.S., Antonellis, A., Fields, L., Doria, A., Orban, T., Saad, M., Warram, J.H., Montminy, M., and Krolewski, A.S. 1999. Mutations in NEUROD1 are associated with the development of type 2 diabetes mellitus. Nat. Genet. 23: 323-328.

Minichiello, L., Piehl, F., Vazquez, E., Schimmang, T., Hokfelt, T., Represa, J., and Klein, R. 1995. Differential effects of combined trk receptor mutations on dorsal root ganglion and inner ear sensory neurons. Development 121: 4067-4075.

Mitchell, C. and Clemis, J.D. 1977. Audiograms derived from the brain stem response. Laryngoscope 87: 2016-2022.

Miyata, T., Maeda, T., and Lee, J.E. 1999. NeuroD is required for differentiation of the granule cells in the cerebellum and hippocampus. Genes \& Dev. 13: 1647-1652.

Morrow, E.M., Furukawa, T., Lee, J.E., and Cepko, C.L. 1999. NeuroD regulates multiple functions in the developing neural retina in rodent. Development 126: 23-36.

Morsli, H., Choo, D., Ryan, A., Johnson, R., and Wu, D.K. 1998. Development of the mouse inner ear and origin of its sensory organs. J. Neurosci. 18: 3327-3335.

Morsli, H., Tuorto, F., Choo, D., Postiglione, M.P., Simeone, A., and Wu, D.K. 1999. Otx1 and Otx2 activities are required for the normal development of the mouse inner ear. Development 126: 2335-2343.

Mutoh, H., Naya, F.J., Tsai, M.J., and Leiter, A.B. 1998. The basic helix-loop-helix protein BETA2 interacts with p300 to coordinate differentiation of secretin-expressing enteroendocrine cells. Genes \& Dev. 12: 820-830.

Naya, F.J., Stellrecht, C.M., and Tsai, M.J. 1995. Tissue-specific regulation of the insulin gene by a novel basic helix-loophelix transcription factor. Genes \& Dev. 9: 1009-1019.

Naya, F.J., Huang, H.P., Qiu, Y., Mutoh, H., DeMayo, F.J., Leiter, A.B., and Tsai, M.J. 1997. Diabetes, defective pancreatic morphogenesis, and abnormal enteroendocrine differentiation in BETA2/neuroD-deficient mice. Genes \& Dev. 11: 2323-2334.

Noden, D.M. and Van de Water, T.R. 1992. Genetic analyses of mammalian ear development. Trends Neurosci. 15: 235237.

Oesterle, E.C., Tsue, T.T., and Rubel, E.W. 1997. Induction of cell proliferation in avian inner ear sensory epithelia by insulin-like growth factor-I and insulin. I. Comp. Neurol. 380: 262-274.

Pirvola, U., Arumae, U., Moshnyakov, M., Palgi, J., Saarma, M., and Ylikoski, J. 1994. Coordinated expression and function of neurotrophins and their receptors in the rat inner ear during target innervation. Hear. Res. 75: 131-144.

Qiu, Y., Cooney, A.J., Kuratani, S., DeMayo, F.J., Tsai, S.Y., and Tsai, M.J. 1994. Spatiotemporal expression patterns of chicken ovalbumin upstream promoter-transcription factors in the developing mouse central nervous system: Evidence for a role in segmental patterning of the diencephalon. Proc. Natl. Acad. Sci. 91: 4451-4455.

Rogers, M.J., Fleming, J., Kiernan, B.W. Mburu, P., Varela, A. Brown, S.D., and Steel, K.P. 1999. Genetic mapping of the 
Liu et al.

whirler mutation. Mamm. Genome 10: 513-519.

Rubel, E.W. 1978 Ontogeny of structure and function in the vertebrate auditory system. In Handbook of sensory physiology, Vol. 9 (ed. M. Jacobson), pp. 135-237. Springer, Berlin.

Ruben, J. 1967. Development of the inner ear of the mouse: A radioautographic study of terminal mitoses. Acta Otolaryngol. 220: 1-44.

Rüsch, A., Erway, L.C., Oliver, D., Vennstrom, B., and Forrest, D. 1998a. Thyroid hormone receptor $\beta$-dependent expression of a potassium conductance in inner hair cells at the onset of hearing. Proc. Natl. Acad. Sci. 95: 15758-15762.

Rüsch, A., Lysakowski, A., and Eatock, R.A. 1998b. Postnatal development of type I and II hair cells in the mouse utricle: Acquisition of voltage-gated conductances and differentiated morphology. J. Neurosci. 18: 7487-7501.

Schimmang, T, Minichiello, L., Vazquez, E., San Jose, I., Giraldez, F., Klein, R., and Represa, J. 1995. Developing inner ear sensory neurons require TrkB and TrkC receptors for innervation of their peripheral targets. Development 121: 33813391

Schwab, M.H., Bartholomae, A., Heimrich, B., Feldmeyer, D., Druffel-Augustin, S., Goebbels, S., Naya, F.J., Zhao, S., Frotscher, M., Tsai, M.-J., and Nave, K.-A. 2000. Neuronal basic helix-loop-helix proteins (NEX and BETA2/Neuro D) regulate terminal granule cell differentiation in the hippocampus. J. Neurosci. 20: 3714-3724

Sher, A.E. 1971. The embryonic and postnatal development of the inner ear of the mouse. Acta Otolaryngol. (Suppl.) 285: $1-77$.

Silos-Santiago, I., Fagan, A.M., Garber, M., Fritzsch, B., and Barbacid, M. 1997. Severe sensory deficits but normal CNS development in newborn mice lacking TrkB and TrkC tyrosine protein kinase receptors. Euro. J. Neurosci. 9: 2045-2056

Swanson, G.J., Howard, M., and Lewis, J. 1990. Epithelial autonomy in the development of the inner ear of a bird embryo. Dev. Biol. 137: 243-257.

Torres, M. and Giraldez, F. 1998. The development of the vertebrate inner ear. Mech. Dev. 71: 5-21.

Torres, M., Gomez-Pardo, E., and Gruss, P. 1996. Pax2 contributes to inner ear patterning and optic nerve trajectory. Development 122: 3381-3391.

Van de Water, T.R. 1986. Determinants of neurons-sensory receptor cell interaction during development of the inner ear. Hear. Res. 22: 265-77.

Van de Water, T.R. and Represa, J. 1991. Tissue interactions and growth factors that control development of the inner ear: Neural tube-otic anlage interaction. Ann. N Y Acad. Sci. 630: 116-128.

Vendrell, V., Carnicero, E., Giraldez, F., Alonso, M.T., and Schimmang, T. 2000. Induction of inner ear fate by FGF3. Development 127: 2011-2019.

Wang, W., Van De Water, T. R., and Lufkin, T. 1998. Inner ear and maternal reproductive defects in mice lacking the $\mathrm{Hmx} 3$ homeobox gene. Development 125: 621-634. 


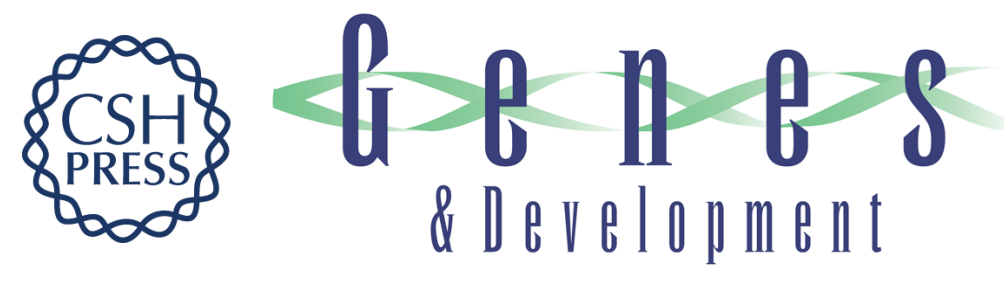

\section{Essential role of BETA2/NeuroD1 in development of the vestibular and auditory systems}

Min Liu, Fred A. Pereira, Steven D. Price, et al.

Genes Dev. 2000, 14:

Access the most recent version at doi:10.1101/gad.840500

References This article cites 66 articles, 25 of which can be accessed free at: http://genesdev.cshlp.org/content/14/22/2839.full.html\#ref-list-1

License

Email Alerting

Receive free email alerts when new articles cite this article - sign up in the box at the top Service right corner of the article or click here.

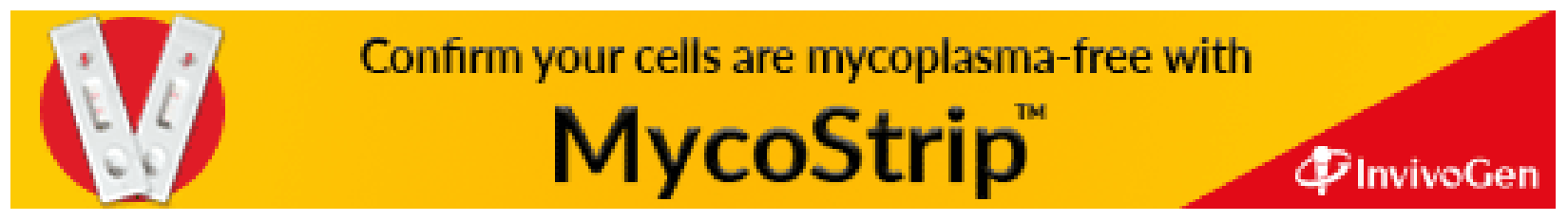

